\title{
Pentecostalismo como respuesta al racionalismo occidental y sus aportes al cristianismo y sociedad latinoamericana
}

\author{
José Adán Maravilla Arévalo \\ jamaravillaa@ujmd.edu.sv \\ Doctor en Medicina, Master en Salud Pública \\ Estudiante de Licenciatura en Teología \\ Escuela Superior de Estudios Teológicos Semper Reformanda \\ Docente coordinador de la Cátedra de Antropología Filosófica \\ Universidad Dr. José Matías Delgado. \\ Recibido:20/02/2018 \\ Aceptado: 09/03/18
}

\section{Resumen}

Las predicciones de los principales teóricos naturalistas no han sido nada favorables para el cristianismo, todos concuerdan que a medida la ciencia aumente, la religión -haciendo énfasis al cristianismo- irá disminuyendo hasta desaparecer. Contrario a este argumento, durante el siglo $\mathrm{XX}$ se desencadenó un crecimiento acelerado del cristianismo, y este crecimiento ha sido en la línea pentecostés. Latinoamérica es la zona geográfica donde más impacto ha tenido el pentecostalismo, en este trabajo se muestra un resumen de los aportes que ha dejado al cristianismo y a la sociedad en América Latina.

Palabras Clave.

Cosmovisión, naturalismo, pentecostalismo, pentecostés, pentecostal, racionalismo, El Salvador.

\section{Pentecostalism as the response to the Western rationalism and its contribution to Christianism and to the Latin-American society Summary}

The predictions of the main naturalistic theorists have not been favorable for Christianity, all agree that as science increases, religion (emphasizing Christianity) will diminish until it disappears. Contrary to this argument, during the twentieth century an accelerated growth of Christianity was unleashed, and this growth has been on the Pentecostal line. Latin America is the geographical area where Pentecostalism has had the most impact, and in this work a summary of the contributions it has left to Christianity and to society in Latin America is shown.

Keywords

Worldview, naturalism, Pentecostalism, Pentecost, Pentecostal, rationalism, El Salvador. 


\section{Introducción}

El racionalismo occidental -que considera la razón como fuente principal y única base de valor del conocimiento humano en general- hizo augurar desde el siglo XIX, que la religión cristiana perdería paulatinamente su influencia sobre la sociedad y la cultura y que, finalmente, su desaparición ocurriría espontáneamente, como producto de la difusión de la ciencia (García Leguizamón, 2012). Sus principales teóricos, no dudaron en proclamar y "profetizar" la extinción del cristianismo a manos del avance científico, no sólo como un resultado de este, sino más bien como una necesidad para el desarrollo de la humanidad.

Ya en 1844, Marx afirmaba que "la eliminación de la religión como ilusoria felicidad del pueblo, es la condición para su felicidad real" (Marx, 2005).

Luego en 1927, Freud describió la religión como una "ilusión", producto de un sentimiento infantil de indefensión proyectado en la imagen un padre todopoderoso; afirmó que con el progreso de las ciencias que permiten la aceptación humana de dicha impotencia, tal sentimiento desaparecería (Freud, 2014).

En 1966, el antropólogo Anthony Wallace sentenció que el destino evolutivo de la religión era su extinción: "La creencia en seres y fuerzas sobrenaturales que afectan a la naturaleza sin someterse a sus leyes se deteriorará hasta llegar a convertirse en un interesante recuerdo histórico [...] La creencia en poderes sobrenaturales está condenada a desvanecerse, en todo el mundo, como consecuencia de la creciente difusión del conocimiento científico" (Wax, Smith, \& Wallace, 1968).

Así, la influencia de estos y otros pensadores que tenían a la razón humana como el juez último en cuanto a la verdad, llevó a un sesgo en la ciencia, el cual consiste en aceptar la teoría evolucionista como una ley, ignorando que tras la teoría evolucionista se encuentra una cosmovisión Naturalista-Materialista (Sire, 2006), que establece que la materia existe eternamente, y es lo único que hay. No hay Dios.

Con estas presuposiciones -racionalismo, naturalismo y evolucionismo- se empezó un adoctrinamiento que se ha apoderado de los sistemas educativos, desde temprana edad se nos muestran como verdad absoluta e incuestionable (Oktar, 2006). Los frutos de este adoctrinamiento no se hicieron esperar, en 1967, el sociólogo Peter Berger constataba que el mundo occidental moderno, producía cada vez más individuos que miran el mundo y sus propias vidas, sin el beneficio de las interpretaciones religiosas (Berger, 1967).

En el siglo XXI, el biólogo Richard Dawkins, ateo militante contra la religión, la ha calificado como "delusion" esto es, una creencia falsa que se mantiene a pesar de las evidencias en contra, anotando que "cuando una persona padece de un delirio se habla de locura; cuando son muchas personas las que lo padecen, se habla de religión" (Dawkins, 2006), dando continuidad a la postura anti religiosa, 
predominante en las ciencias, pero a la vez, es una clara expresión de desilusión y frustración, ante el fracaso de las predicciones hechas por sus predecesores durante el siglo XIX.

En resumen, las predicciones de los principales teóricos naturalistas no han sido nada favorables para el cristianismo, todos concuerdan que a medida la ciencia aumente, la religión (haciendo énfasis al cristianismo) irá disminuyendo hasta desaparecer. Contrario a este argumento, durante el siglo XX se desencadenó un crecimiento acelerado del cristianismo, $\mathrm{y}$ este crecimiento ha sido en la línea pentecostés.

Latinoamérica es la zona geográfica donde más impacto ha tenido el pentecostalismo $\mathrm{y}$, en este trabajo, se muestra un resumen de los aportes que ha dejado al cristianismo y a la sociedad en América Latina, basado en una revisión bibliográfica tomando las palabras clave "pentecostés, pentecostalismo, pentecostal" delimitado geográficamente a artículos que estudian el pentecostalismo en el contexto latinoamericano, sin distinguir las múltiples líneas doctrinales que este movimiento tiene; pero excluyendo a los estudios que hacen referencia al Neopentecostalismo, ya que la mayoría de autores consideran a este como otra línea religiosa.

\section{Aportes del Pentecostalismo al Cristianismo en Latinoamérica:}

1. Surge como respuesta al modernismo, ya que es un movimiento reaccionario a una modernidad secularizada que ha removido la centralidad de Dios
(Orellana Gallardo, 2012). El protestantismo surgió en una época en que la religión para muchos iba en franco declive, en una época dominada por el espíritu científico y en que lo religioso era considerado un elemento anticuado y de retraso, en una época que Marx, Nietzsche y Freud, habían afirmado sin vacilaciones que la religión iba a desaparecer. Este aporte trasciende a la región latinoamericana, ya que el movimiento pentecostés nació en el primer mundo; pero rápidamente se extendió a los países en desarrolla tanto en América como en África, y este crecimiento echó por tierra las proyecciones modernistas.

2. Aporta un carácter personal al acto religioso, reaccionando de una manera "vivencial", experimentando la religiosidad de una manera "directa", mediante la glosolalia, el éxtasis u otras formas corporales (Orellana Gallardo, 2012). Sosteniendo que los rituales litúrgicos eran menos importantes que la experiencia individual de la conversión, en cuanto esta representa un acto consciente que acerca a la persona a Cristo y la hace objeto de su perdón (García Leguizamón, 2012). El carácter vivencial de pentecostalismo contrasta con la "rigidez" de las Iglesias fundamentalistas, esto le permitió un rápido crecimiento en Estados Unidos, contraste que fue aún mayor en Latinoamérica al 
enfrentarse a una Iglesia Católica con una liturgia rígida y distante.

3. Brinda un carácter moral a la sociedad, por ejemplo, se demostró una fuerte asociación entre la postergación de la iniciación sexual y el pentecostalismo en Brasil (Verona \& Regnerus, 2014). También está demostrado un alto impacto en programas de rehabilitación social, como rehabilitación a privados de libertad, adicciones y alcoholismo (Marín Alarcón \& Bahamondes González, 2017).

4. Genera espacios de participación y liderazgo a las mujeres. En Latinoamérica, en sociedades tradicionalmente machistas, donde la mujer está en desventaja social y económica, el pentecostalismo brinda espacios de participación social (grupos de oración, evangelismo, sociedad femenil, etc.) y liderazgo a las mujeres, permitiéndoles cargos de pastoras, ministras y profetisas (Mansilla Agüero \& Orellana, 2014). Si este punto lo enmarcamos en el contexto de los grupos socioeconómicos de mayor crecimiento del pentecostalismo, que son la clase baja y media baja, se vuelve aún más relevante.

5. Genera confianza en sus miembros para expresar sus emociones y pensamientos. Un marco hermenéutico centrado en la experiencia personal, permite al miembro pentecostés libertad de expresión, libertad que se transmite al campo socio-político, obteniendo la sociedad ciudadanos informados y definidos políticamente (Panotto, 2014). Este punto es contrario a lo asegurado por Marx, quien afirmó que "la religión es el opio de los pueblos" (Marx, 2005).

6. Fomenta el sentido de pertenencia. En una sociedad Posmoderna e individualista, el pentecostalismo brinda al individuo un sentimiento de pertenencia al grupo, de integración social, pues en la Iglesia pentecostal las personas reciben reconocimiento social, orientación cognitiva y moral, fuertes estímulos emocionales e inserción en lógicas de progreso modernas. En estos procesos se evidencia una tensión entre individualización y colectivización o entre libertad individual y sometimiento a una comunidad, dialéctica irresuelta que, además, es propia de la modernidad, así en las iglesias pentecostés, sus reuniones y la fraternidad que se conforma en ellas brindan una respuesta a este conflicto (Sarrazin \& Arango, 2017).

7. Gran migración del catolicismo al cristianismo evangélico, observado cuando personas adultas deciden migrar de la Iglesia católica a una Iglesia pentecostal, esta migración es vivida por el individuo como la expresión de su libertad personal y como una emancipación de la tradición de sus ancestros (Sarrazin \& Arango, 2017). El amplio y fuerte dominio católico en Latinoamérica, heredado durante la colonia, impidió por 
años el crecimiento del cristianismo evangélico en esta región, por tanto, esta migración religiosa es un aporte sin igual del protestantismo al cristianismo evangélico.

8. La rápida expansión es indiscutiblemente el mayor aporte del Pentecostalismo al Cristianismo, en poco más de un siglo de existencia, ha mostrado un crecimiento sin precedente en la historia de los movimientos religiosos: si en 1901 todo había iniciado con 40 creyentes, en 1945 se contaban ya 16 millones y en 1975, 96 millones de seguidores en el planeta, en 2007 el cardenal Walter Kasper estimó aproximadamente 400 millones de pentecostales. Aproximadamente el $85 \%$ de los evangélicos latinoamericanos son pentecostales y en El Salvador, entre 1960 y 1985, la población evangélica se quintuplicó (García Leguizamón, 2012).

En el ámbito social el pentecostalismo afirma el carácter moral, brinda espacios de participación y liderazgo a las mujeres, genera confianza en sus miembros para expresar sus pensamientos y fomenta el sentido de pertenencia.

Para el cristianismo, el movimiento pentecostés brindó una liturgia más personal, espacios de participación para las mujeres e involucramiento de la iglesia en los problemas sociales como adicciones $\mathrm{y}$ alcoholismo, factores que fueron clave para el contexto histórico latinoamericano, de fuerte tradición católica.

El carácter vivencial del pentecostalismo, fue la respuesta al racionalismo humanista. Contrario a todas las predicciones hechas por los naturalistashumanistas, el cristianismo no ha disminuido a pesar del aumento de la ciencia. Indiscutiblemente la razón humana no pudo sustituir a la fe en Jesucristo. Sobre todo, cuando la "razón humana" está en crisis como ahora los está, ya que el posmodernismo ha derribado cualquier verdad absoluta que la razón logró conquistar.

Pero, también, el pentecostalismo se enfrenta a nuevos retos, intentando satisfacer a un sujeto religioso que circunscribe lo divino en torno a un yo emocional, materialista e individualista (Mansilla, Leiva, \& Muñoz, 2017). A este yo materialista, se suma una sociedad en desamparo (Próchino, Paradivini, \& Gonçalves, 2008), brindando el ambiente ideal para que el Neopentecostalismo, con sus promesas de curación y milagros, gane terreno como movimiento religioso (Algranti, 2008).

Por lo tanto, no sólo las iglesias pentecostés, sino, la Iglesia de Cristo deben tener un sólido fundamento teológico y una cosmovisión cristiana, para hacer frente a los retos de un mundo posmoderno.

\section{Bibliografía}

Algranti, J. (2008). De la sanidad del cuerpo a la sanidad del alma: estudio sobre la lógica de construcción de las identidades colectivas en el neo-pentecostalismo argentino. Religião \& Sociedade, 28(2), 179-209.

Berger, P. L. (1967). The Social Reality of Religion. London, Faber.

Dawkins, R. (2006). The God Delusion. 
Freud, S. (2014). El porvenir de una ilusión. FV Éditions.

García Leguizamón, F. (2012). Protestants, Evangelicals and Pentecostals: Some preliminary conceptual clarifications in a social research field. Folios, (36), 171-187.

Mansilla Agüero, M. Á., \& Orellana, L. (2014). Female pentecostal pastors: metaphors about women's leadership in the Pentecostal Evangelical Church (1972-2001). Memoria Y Sociedad: Revista Del Departamento de Historia Y Geografia, 18(36), 83-98.

Mansilla, M. Á., Leiva, S., \& Muñoz, W. (2017). Pospentecostalismo: del fundacionalismo al postfundacionalismo pentecostal chileno. Cinta de Moebio, (59), 172-185.

Marín Alarcón, N., \& Bahamondes González, L. A. (2017). Adicciones, disciplinamiento y pentecostalismo carcelario en Chile: reflexiones para iniciar un debate. Sociology of Religion, 27(48), 214-236.

Marx, K. (2005). Crítica de la filosofía del derecho de Hegel. Ediciones del Signo.

Oktar, H. Y.-A. (2006). El engaño del evolucionismo. (G. Publishing, Ed.). Global Publishing.

Orellana Gallardo, F. (2012). Fundamentalismo y pentecostalismo como expresión de religiosidades antagónicas, y un significativo lazo en común. Polis , 11(32), 441-459.

Panotto, N. (2014). Pentecostalism and the Construction of Socio-Political Identities. Desafíos, 26(2), 73-96.

Próchino, C. C. S. C., Paradivini, J. L. L., \& Gonçalves, M. A. (2008). Subjective and cure in the Neopentecostal. Psicologia: Ciência E Profissão, 28(3), 586-601.

Sarrazin, J. P., \& Arango, P. (2017). The Christian Alternative in Late Modernity. Reasons of Religious Migration from Catholicism towards Pentecostalism. Folios, (46), 41-54.

Sire, J. W. (2006). El Universo de al lado. (W. L. M. Desafio, Ed.). World Literature Ministries/Libros Desafio.

Verona, A. P. A., \& Regnerus, M. (2014). Pentecostalism and premarital sexual initiation in Brazil. Revista Brasileira de Estudos de Populacao, 31(1), 99-115.

Wax, M. L., Smith, B. L., \& Wallace, A. F. C. (1968). Religion: An Anthropological View. Journal for the Scientific Study of Religion, 7(1), 112. 